\title{
Case Report \\ Collagenous Fibroma (Desmoplastic Fibroblastoma) with Vertebral Body Erosion
}

\author{
Vladimir Osipov ${ }^{1}$ and Guillermo F. Carrera ${ }^{2}$ \\ ${ }^{1}$ Department of Patholog, Medical College of Wisconsin, 9200 West Wisconsin Avenue, Milwaukee, 53226, USA \\ ${ }^{2}$ Department of Radiology, Medical College of Wisconsin, 9200 West Wisconsin Avenue, Milwaukee, 53226, USA
}

Correspondence should be addressed to Vladimir Osipov, vosipov@mcw.edu

Received 17 October 2008; Accepted 6 April 2009

Recommended by Michael Leahy

Collagenous fibroma (desmoplastic fibroblastoma) is a recently described rare benign tumor affecting mainly males in the fifth through seventh decades. This tumor occurs predominantly in the peripheral sites, with predilection for upper and lower extremities. The patients present with a painless mass of involving subcutis, with one quarter of all cases involving skeletal muscle. Both radiographically and histologically these tumors are well-circumscribed small lesions from one to several centimeters in diameter, though lesions as large as $20 \mathrm{~cm}$ have been reported. We report a case of collagenous fibroma presenting symptomatically as a $2.4 \mathrm{~cm}$ mass within the pedicle and adjacent transverse process of the L5 vertebral segment. Bone erosion by desmoplastic fibroblastoma is very rare event. This tumor should be in the differential diagnosis of the soft tissue lesions presenting with bony erosion.

Copyright ( 2009 V. Osipov and G. F. Carrera. This is an open access article distributed under the Creative Commons Attribution License, which permits unrestricted use, distribution, and reproduction in any medium, provided the original work is properly cited.

\section{Introduction}

Collagenous fibroma (desmoplastic fibroblastoma) is a recently defined entity first described by Evans in 1995 [1]. Since then, fewer than 100 cases have been reported with the largest series published by Miettinen and Fetsch [2]. Collagenous fibroma is a benign fibrous soft tissue tumor typically arising in the subcutaneous tissue or skeletal muscle of adults. A wide age range is affected, but it is most common in the fifth through seventh decades. Men are affected four times more commonly than women. Collagenous fibroma has a wide anatomic distribution affecting mainly extremities and presents as a slowly growing, painless mass, ranging from 1 to $20 \mathrm{~cm}$ in maximum dimension [2]. Surgery is the treatment of choice, with no reported tumor recurrences. Differential diagnosis includes desmoid tumor, Gardner fibroma, and nuchal-type fibroma. Cases with cytogenetic abnormalities have been reported suggesting a neoplastic nature for this tumor [3]. Bone erosion is an extremely rare event with only one case previously published $[4]$.

\section{Case Report}

The patient, a 56-year-old woman, presented with right L5 radicular pain, worse at night, which subsequently improved with Neurontin (Gabapentin) therapy. Imaging evaluation including plain films, CT, and MRI showed a lytic, minimally expansile intraosseous soft-tissue mass occupying the right L5 pedicle and extending into the adjacent transverse process (Figure 1). The lesion measured $2.4 \mathrm{~cm}$ in greatest dimension. The lesion was lytic, expansile and well-defined on CT. MRI showed heterogeneous intermediate signal intensity on T2 and T1 weighted images with scattered areas of low signal intensity on both sequences, and diffuse minimally heterogeneous enhancement following intravenous Gadolinium (Figure 2). There was degenerative change in the adjacent facet joint. Differential diagnosis included osteoblastoma, giant cell tumor, and metastasis. A CT-directed core biopsy was performed using a 14 gauge coaxial system. Histology revealed a uniformly paucicellular tumor (Figure 3 ). There were widely spaced, bland spindle to stellate shaped cells embedded in a dense fibrous stroma 


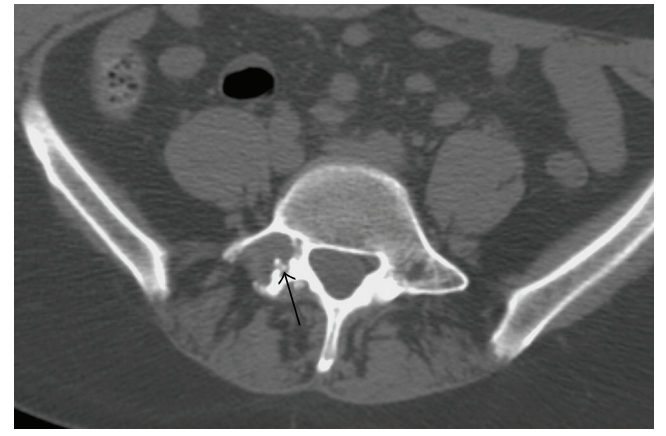

FIgURE 1: CT image shows a well-circumscribed, minimally expansile lytic lesion in the right pedicle and adjacent transverse process of L5. Tiny densities (arrow) represented bony fragments from adjacent degenerated facet joint.

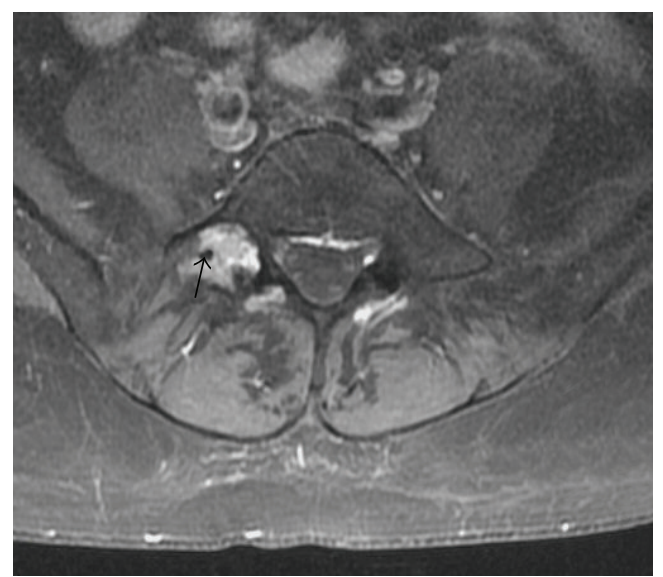

Figure 2: Fat-saturated T1 post-Gadolinium images show mixed intermediate signal in the lesion with moderate heterogeneous generalized enhancement. There is no adjacent edema or reaction in the bone or soft tissues. Small areas of low signal (arrows) are present.

with homogeneous collagen bundles (Figure 4). There was no cytoatypia. Mitotic figures and necrosis were absent. Focally, fragments of unremarkable bone were present. The tumor showed entrapment of the adipose tissue and skeletal muscle at the periphery. Vimentin immunohistochemical stain showed positivity within the spindle cells. Smooth muscle actin showed very faint focal positivity. Congo red histochemical stain was negative, excluding the possibility of amyloidosis. Two years later, patient had no evidence of recurrence and was symptoms-free.

\section{Discussion}

The most important information related to the lesions in the differential diagnosis of collagenous fibroma is summarized in Table 1, created using the information found in the recent issue of WHO Tumors of Soft Tissue and Bone [5].

One additional differential diagnosis not included in this table is a "burned-out" phase of nodular fasciitis. Whether one wishes to interpret desmoplastic fibroblastoma as a

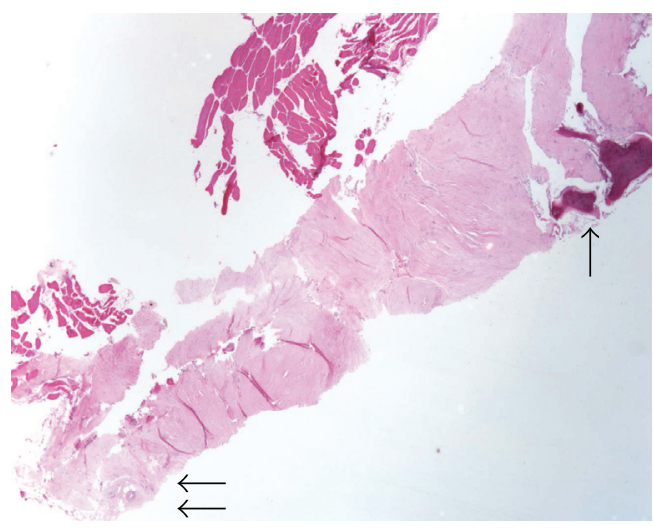

Figure 3: Full length Tru-cut biopsy of the tumor. Note the entrapment of the skeletal muscle and adipose tissue at the periphery (double arrow) and involvement of the bone at the other end (single arrow). (H\&E, 40X).

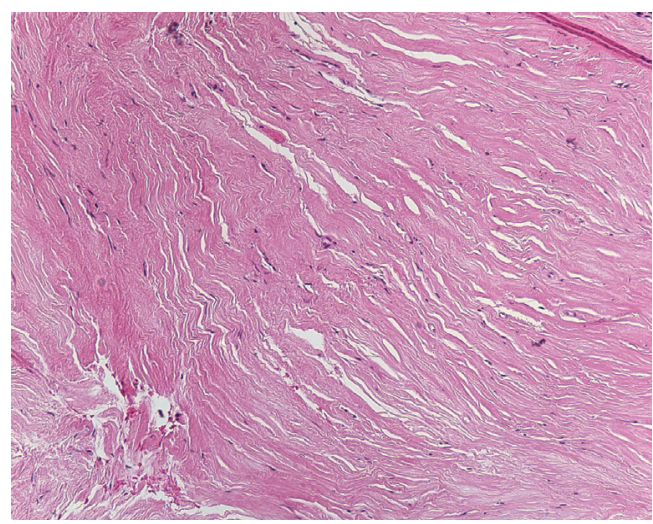

Figure 4: Hypocellular densely collagenous stroma of the tumor. (H\&E,400X).

"burnt-out" phase of a nodular fasciitis is probably irrelevant for all practical purposes. However, the nodular fasciitis can present similarly to the collagenous fibroma. One of the most recent papers [6] describes a case of a superficial cortical erosion of a long bone.

Our report is unique for several reasons. Our patient presented with pain, while the vast majority of collagenous fibromas are asymptomatic. In addition, bone erosion is a very rare event with only one case previously described [4]. The imaging findings of this lesion match those reported in soft tissue collagenous fibroma $[7,8]$. The plain film findings are nonspecific, and in our case, the lesion consisted of a lytic, minimally expansile focus suggesting slow, nonaggressive growth. No calcifications were visible on radiography or CT. The MRI findings included heterogeneous intermediate signal on both fat and fluid sensitive sequences, minimally heterogeneous diffuse enhancement and focal (in our lesion, very small) areas of persistently low signal suggesting regions of dense acellular collagen aggregates.

Since a significant component of the tumor was at least contiguous with the adjacent soft tissue, the intraosseous component in our case probably represents an erosion of 
TABLE 1: Summary of the clinical, radiographic, and pathological characteristics of the tumors in the differential for collagenous fibroma.

\begin{tabular}{|c|c|c|c|c|}
\hline Tumor type & Age, gender & Location & Imaging & Histology \\
\hline Collagenous fibroma & $\begin{array}{l}\text { Mainly males, between } \\
\text { fifth and seventh decades } \\
\text { of life }\end{array}$ & Extremities & Well-circumscribed & $\begin{array}{l}\text { Hypocellular, with } \\
\text { prominent collagenous } \\
\text { background, entrapment } \\
\text { of the soft tissue at the } \\
\text { periphery. }\end{array}$ \\
\hline $\begin{array}{l}\text { Desmoid tumor } \\
\text { (extra-abdominal) }\end{array}$ & $\begin{array}{l}\text { Puberty-middle age, no } \\
\text { gender predilection }\end{array}$ & $\begin{array}{l}\text { Shoulder, chest wall, back, } \\
\text { thigh, head and neck }\end{array}$ & Poorly defined & $\begin{array}{l}\text { Variably cellular stroma } \\
\text { containing compressed or } \\
\text { distorted blood vessels }\end{array}$ \\
\hline Gardner's fibroma & $\begin{array}{l}\text { Children, adolescents, } \\
\text { no gender predilection }\end{array}$ & $\begin{array}{l}\text { Paraspinal region, back, } \\
\text { chest wall, flank, head and } \\
\text { neck, extremities }\end{array}$ & Poorly defined & $\begin{array}{l}\text { Hypocellular, entrapment } \\
\text { of the soft tissue at the } \\
\text { periphery. Not vascular. }\end{array}$ \\
\hline Nuchal-type fibroma & $\begin{array}{l}\text { Third through fifth } \\
\text { decades of life, male } \\
\text { predilection }\end{array}$ & $\begin{array}{l}\text { Classically in the posterior } \\
\text { neck }\end{array}$ & Poorly defined & $\begin{array}{l}\text { Hypocellular, with } \\
\text { haphazardly arranged } \\
\text { collagen fibers, nerve twigs. }\end{array}$ \\
\hline
\end{tabular}

the vertebral body by the tumor. Interestingly, a peripheral entrapment of the skeletal muscle and adipose tissue was noted histologically (Figure 3), a feature present in over one half of the tumors reported by Miettinen and Fetsch [2]. Other authors also noted this feature [9]. In one report a collagenous fibroma of alveolar bone was reported [10], but the authors stated that there was no osseous involvement with only osteogenic reaction of the subjacent bone.

In summary, collagenous fibroma should be in the differential diagnosis of a well-circumscribed lesion with intraosseous component. Simple excision is recommended in symptomatic patients.

\section{References}

[1] H. L. Evans, "Desmoplastic fibroblastoma: a report of seven cases," The American Journal of Surgical Pathology, vol. 19, no. 9, pp. 1077-1081, 1995.

[2] M. Miettinen and J. F. Fetsch, "Collagenous fibroma (desmoplastic fibroblastoma): a clinicopathologic analysis of 63 cases of a distinctive soft tissue lesion with stellate-shaped fibroblasts," Human Pathology, vol. 29, no. 7, pp. 676-682, 1998.

[3] R. Sciot, I. Samson, H. van den Berghe, B. Van Damme, and P. Dal Cin, "Collagenous fibroma (desmoplastic fibroblastoma): genetic link with fibroma of tendon sheath?" Modern Pathology, vol. 12, no. 6, pp. 565-568, 1999.

[4] I. Beggs, D. S. Salter, and H. D. Dorfman, "Synovial desmoplastic fibroblastoma of hip joint with bone erosion," Skeletal Radiology, vol. 28, no. 7, pp. 402-406, 1999.

[5] World Health Organization Classification of Tumours, Pathology \& Genetics. Tumours of Soft Tissue and Bone, International Agency for Research on Cancer, Lyon, France, 2002.

[6] T. Le Corroller, T. J. Kovacs, and P. Champsaur, "Nodular fasciitis with cortical involvement," Joint Bone Spine, vol. 76, no. 1, pp. 101-103, 2009.

[7] K. R. Walker, L. T. Bui-Mansfield, S. A. Gering, and R. D. Ranlett, "Collagenous fibroma (desmoplastic fibroblastoma) of the shoulder," American Journal of Roentgenology, vol. 183, no. 6, p. 1766, 2004.

[8] R. Shuto, H. Kiyosue, Y. Hori, H. Miyake, K. Kawano, and H. Mori, "CT and MR imaging of desmoplastic fibroblastoma," European Radiology, vol. 12, no. 10, pp. 2474-2476, 2002.
[9] M. Dagli, A. Eryilmaz, A. Acar, S. Kulacoglu, and H. Akmansu, "Collagenous fibroma (desmoplastic fibroblastoma)," Yonsei Medical Journal, vol. 45, no. 5, pp. 941-943, 2004.

[10] C. Cazal, A. Etges, F. C. S. de Almeida, S. C. O. M. de Souza, F. D. Nunes, and V. C. de Araújo, "Collagenous fibroma (desmoplastic fibroblastoma) of alveolar bone: a case report," The Jornal Brasileiro de Patologia e Medicina Laboratorial, vol. 41, no. 3, pp. 185-188, 2005. 


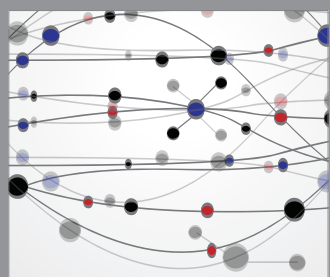

The Scientific World Journal
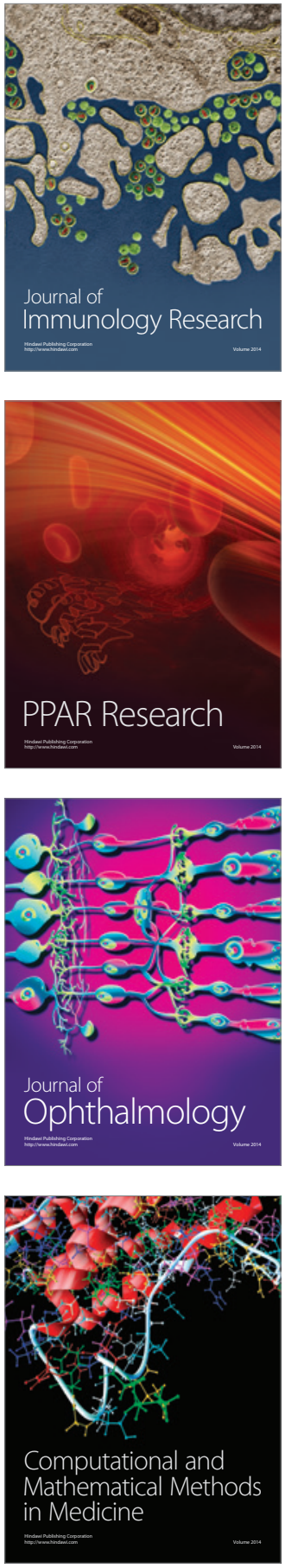

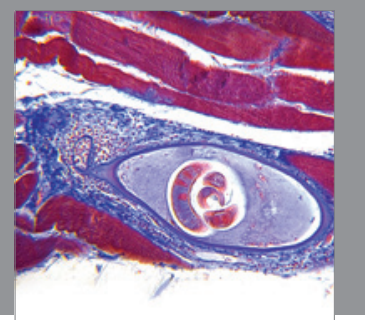

Gastroenterology

Research and Practice
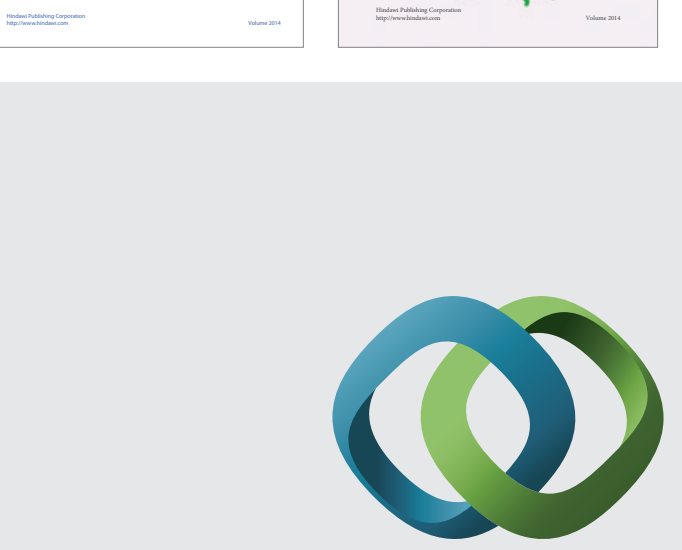

\section{Hindawi}

Submit your manuscripts at

http://www.hindawi.com
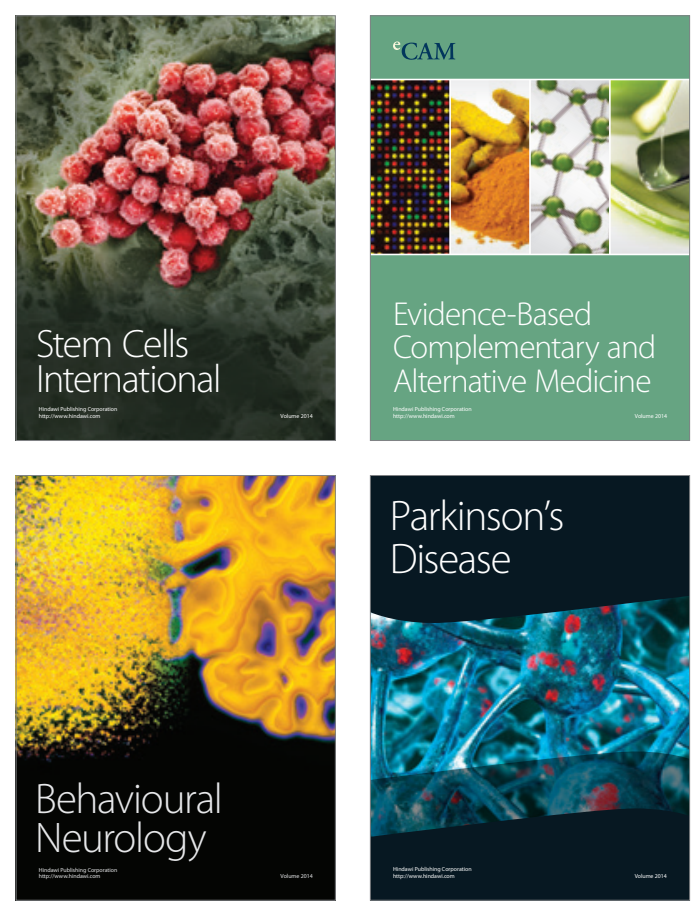

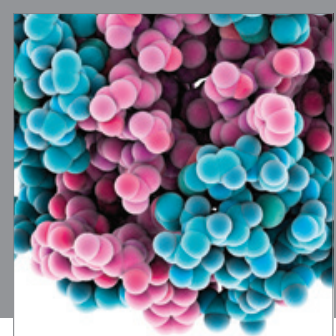

Journal of
Diabetes Research

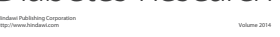

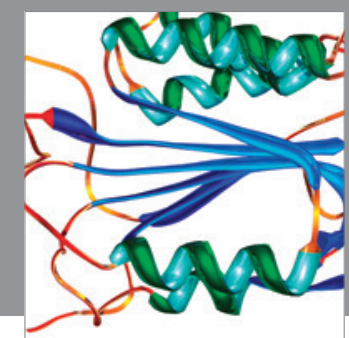

Disease Markers
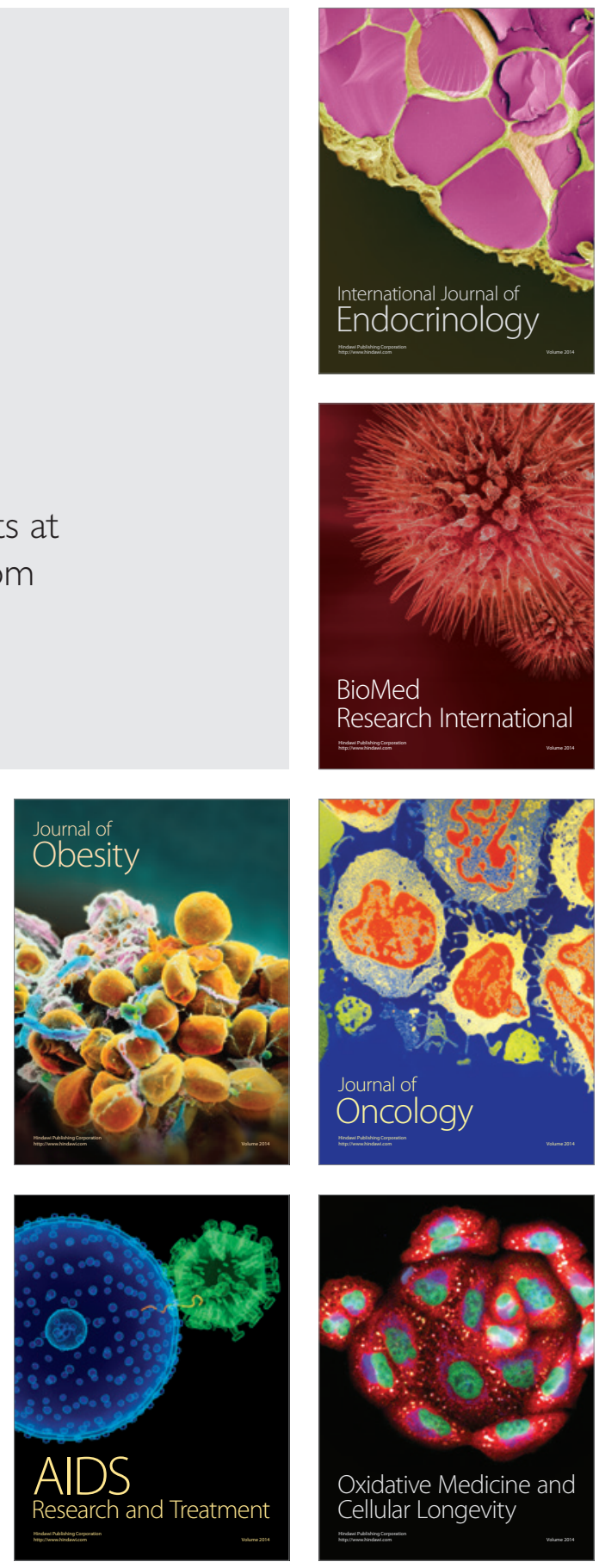